\title{
Use of health services by elderly people post-stroke: a randomized controlled trial
}

\author{
Utilização dos serviços de saúde por idosos após acidente \\ vascular cerebral: ensaio clínico randomizado \\ Utilización de los servicios de salud por ancianos después de un \\ accidente cerebro-vascular: un ensayo clínico randomizado
}

\section{Carla Cristiane Becker Kottwitz Bierhals ${ }^{a}$ Carolina Baltar Day ${ }^{a}$ Duane Mocellin ${ }^{b}$ Naiana Oliveira dos Santos ${ }^{c}$ Mariane Lurdes Predebon ${ }^{\mathrm{a}}$ Fernanda Laís Fengler Dal Pizzol ${ }^{\mathrm{a}}$ Ana Cláudia Fuhrmanna Giullia Garcia de Medeiros ${ }^{b}$ Marines Aires $^{d}$ Lisiane Manganelli Girardi Paskulin ${ }^{\mathrm{a}, \mathrm{e}}$}

How to cite this article: Bierhals CCBK, Day CB, Mocellin D, Santos NO, Predebon ML, Dal Pizzol FLF, Fuhrmann AC, Medeiros GG, Aires M, Paskulin LMG. Use of health services by elderly people post-stroke: a randomized controlled trial. Rev Gaúcha Enferm. 2020;41(esp):e20190138. doi: https://doi.org/10.1590/19831447.2020.20190138 aniversidade Federal do Rio Grande do Sul (UFRGS), Escola de Enfermagem, Programa de Pós-Graduaçăo em Enfermagem. Porto Alegre, Rio Grande do Sul, Brasil.

- Universidade Federal do Rio Grande do Sul (UFRGS), Escola de Enfermagem. Porto Alegre, Rio Grande do Sul, Brasil.

c Universidade Franciscana (UFN). Santa Maria, Rio Grande do Sul, Brasil.

¿ Universidade Integrada do Alto Uruguai e Missões (URI). Frederico Westphalen, Rio Grande do Sul, Brasil.

' Hospital de Clínicas de Porto Alegre (HCPA). Porto Alegre, Rio Grande do Sul, Brasil.

\section{ABSTRACT}

Aim: To verify the relation of a nursing home care educational intervention in the use of health services by elderly people post-stroke.

Methods: A randomized controlled trial conducted with 44 family caregivers of elderly people post-stroke. Data was collected between May/2016 and July/2018 in a hospital in the South of Brazil and at the participants'homes. The intervention group (IG=21) received home visits by nurses after hospital discharge. The control group ( $(G=23)$ had a conventional follow-up in a conventional health services. The Pearson's Chi-Square Test or the Fisher's Exact Test was performed for assessment of the outcome at 60 days and 1 year after discharge. Clinical Trial registration NCT02807012.

Results: Therewas a significant difference regarding the use of hospital outpatient service $(\mathrm{IG}=100 \%, \mathrm{CG}=78.3 \%, \mathrm{p}<0.050) 60$ days after discharge. Conclusion: The great use of outpatient service by the IG demonstrates the effectiveness of nursing educational intervention focused on health care network after discharge.

Keywords: Stroke. Caregivers. Nursing. Clinical trial. Aged. Health services.

\section{RESUMO}

Objetivo:Verificar a relação de intervenção educativa domiciliar de enfermagem na utilização dos serviços de saúde por idosos após Acidente Vascular Cerebral (AVC).

Métodos: Ensaio clínico randomizado com 44 cuidadores familiares de idosos após AVC. Os dados foram coletados entre maio/2016 e julho/2018 em hospital no Sul do Brasil e domicilio dos participantes. 0 grupo intervenção $(G l=21)$ recebeu visitas domiciliares por enfermeiros após a alta hospitalar. 0 grupo controle $(\mathrm{GC}=23)$ manteve acompanhamento convencional na rede de serviços. Realizaram-se Teste Quiquadrado de Pearson ou Exato de Fisher para avaliação do desfecho em 60 dias e 1 ano após a alta. Registro no Clinical Trials NCT02807012.

Resultados: Houve diferença significativa quanto à utilização do serviço ambulatorial hospitalar (Gl=100\%, GC=78,3\%, p<0,050) em 60 dias após a alta.

Conclusão: A maior utilização do serviço ambulatorial pelo Gl demonstra efetividade das intervenções de enfermagem direcionadas à rede de atenção à saúde após a alta.

Palavras-chave: Acidente vascular cerebral. Cuidadores. Enfermagem. Ensaio clínico. Idoso. Serviços de saúde.

\section{RESUMEN}

Objetivo: Verificar la relación de la intervención educativa domiciliaria de enfermería en la utilización de los servicios de salud por ancianos después de un Accidente Cerebro-Vascular (ACV).

Métodos: Ensayo clínico controlado realizado con 44 cuidadores familiares de ancianos después de un ACV. Los datos se recolectaron entre mayo de 2016 y julio de 2018 en un hospital del sur de Brasil y en los domicilios de los participantes. El grupo de intervención (Gl =21) recibió visitas domiciliarias de enfermeros luego del alta hospitalaria. El grupo de control ( $G C=23$ ) mantuvo un seguimiento convencional en la red de servicios. El desenlace fue evaluado a los 60 días y 1 año después del alta. Se realizaron las pruebas Chi-cuadrado de Pearson o Exacta de Fisher para evaluar el desenlace a los 60 días y 1 año después del alta. Registro de ensayo clínico NCT02807012.

Resultados: Se registró una diferencia significativa en la utilización del servicio ambulatorio hospitalario $(G \mid=100 \%, G C=78,3 \%, p<0,050)$ 60 días después del alta.

Conclusión: El mayor uso del servicio ambulatorio por parte del GI demuestra la efectividad de las intervenciones educativas de enfermería, enfocadas en la red de atención a la salud luego del alta hospitalaria.

Palabras clave: Accidente cerebrovascular. Cuidadores. Enfermería. Ensayo clínico. Anciano. Servicios de salud. 


\section{口 INTRODUCTION}

The stroke is the most common cerebrovascular disease and one of the major causes of hospitalization in the elderly ${ }^{(1)}$. The growth of the elderly population increases the demand for health services in the Brazilian scenario ${ }^{(2)}$.

Many stroke patients are readmitted within the first year after discharge. These readmissions are due to problems found in the chronic phase of the disease, such as functional disability, stroke complications and comorbidities ${ }^{(3)}$. Hospital readmissions may be related to gaps in quality of care after the stroke, especially for patients returning home after hospital discharge ${ }^{(4)}$. Proper discharge planning and implementation of care transition programs can contribute to reducing these readmissions ${ }^{(5)}$.

Considering that after hospital discharge, the care of elderly patients with stroke, often complex, is the responsibility of the family at home, it is necessary to transition from hospital to home care, in view of changes in the care perspective, adapting the care process ${ }^{(6)}$. In this perspective, it is important to establish an articulation between the services included in the care network, from hospital care to Primary Health Care, promoting the integrity of care to the user and their family.

A structured program of care transition from hospital to home reduces the length of hospital stay of the elderly and their readmissions, and increases their satisfaction with care $^{(7)}$. In the international context, studies have explored the effects of care transition programs on the use of health services by dependent or stroke elderly patients ${ }^{(8-12)}$.

A group of French researchers has evaluated the impact of a hospital-to-home care transition program for elderly patients. The program is being implemented in three moments: during hospitalization, at discharge and four weeks after they return home. During the elderly's hospitalization, a nurse is responsible for all the information about their health condition, discharge plan, transitional care and contact with primary health care. At discharge, this professional checks whether the prescriptions are in accordance with the discharge plan and whether the patient and the family caregivers understand all the information. After discharge, the nurse monitors the participants through telephone calls and home visits for four weeks to identify their difficulties with care and to provide guidance. Readmissions, demand for emergency services, mortality, and the elderly's satisfaction with the program will be evaluated ${ }^{(11)}$.

Nursing home care educational intervention studies that guide the use of health services after stroke are still incipient in Brazil. It is necessary to conduct research studies in this area within the national context, given the magnitude of the disease in the elderly population and in the perspective of supporting the constitution of the care network. It is believed that this study can contribute to the practice of nurses working in the care of the elderly with stroke and their caregiver, in addition to assisting health service managers in the development of strategies to serve this population. Therefore, the study aimed verify the relation of a nursing home care educational intervention in the use of health services by elderly people post-stroke. This paper is taken from a doctoral dissertation(13).

\section{DETHODS}

A Randomized Controlled Trial (RCT), blinded to outcome assessment. It is part of a larger RCT called "Nursing Home Care Intervention Post Stroke" (SHARE), under registration NCT02807012 in the Clinical Trials.

The study included family caregivers of elderly people with stroke who were treated at the Special Care Unit for Strokes (Unidade de Cuidados Especiais de AVC, UCE-AVC) of a general, public and referral hospital in the South of Brazil, specialized in this type of patient. Inclusion criteria included the following: being a family caregiver of elderly people with stroke, providing unpaid care, declaring responsibility for the most part of care for the elderly and being over 18 years old. Regarding the elderly: medical diagnosis of first stroke with functional sequelae, identified by a minimum score of 2 in the Modified Rankin Scale (mRankin) ${ }^{(14)}$ at the time of discharge, and residing within $20 \mathrm{~km}$ from the hospital. Caregivers of elderly inpatients or the ones who were referred to the Home Care Service (Serviço de Atenção Domiciliar, SAD) of Porto Alegre and those caregivers who refused to receive home visits (HV) were excluded.

The sample consisted of 48 participants, calculated by the outcome of "caregiver's burden" from the umbrella study (SHARE), considering a confidence level of 95\%, statistical power of $80 \%$, and sample loss of $20 \%$. Twenty-four participants were allocated to the intervention group (IG) and 24 to the control group (CG) ${ }^{(15)}$.

Participants were recruited from May 2016 to July 2017 during hospitalization. At this moment, identification, socio-demographic (gender, age, schooling, marital status, family income and professional status) and health condition data of the elderly (type of stroke, morbidities, mRankin scale and Functional Independence Measure - MIF) were collected. As for the caregiver, socio-demographic (gender, age, schooling, marital 
status), health condition (health problems, morbidities), and caregiver status information (relationship with the elderly, whether they reside with the elderly and for how long, previous experience of care, days as a caregiver, whether they received support for care and the type of support) were collected. Both questionnaires were prepared for this study.

Within seven days after hospital discharge, all participants received an $\mathrm{HV}$ from two research assistants to collect baseline data, and the MIF was applied to verify the elderly's level of independence with respect to care. After baseline data collection, participants were randomized between the IG and the CG by a researcher with no involvement with the intervention offered, through a numerical list generated by the randomization.com site.

The IG was systematically monitored by a pair of nurses by means of three HVs with an average duration of one hour each, at approximately 14, 21 and 30 days after discharge, according to the protocol ${ }^{(15)}$. The intervention included verbal orientations and visual demonstrations on care with the purpose of supporting caregivers in the acquisition of skills to perform the daily activities of the elderly at home and in the use of the health care network. The intervention also contemplated guidelines on how to obtain the Unified Health System (Sistema Único de Saúde, SUS) card, to keep the follow-up of the elderlies in the health unit where they had a bond, how to get special medications, enteral diets, diapers and dressing material, among others. In addition, they were advised on the use of hospital emergency rooms, emergency home care services or urgent care, according to the elderlies' health status. The CG did not receive the intervention and had the conventional follow-up in the service network to which they had access. It is noteworthy that after hospital discharge, all patients of the UCE-AVC are referred to the outpatient service of the hospital for follow-up with professionals of the multidisciplinary team, including the neurology and physiotherapy team, speech therapists and nutritionists. The frequency and duration of this follow-up is according to the patient's need.

The use of health services by the elderly was assessed through a questionnaire designed for the study, applied by research assistants in the assessment $\mathrm{HV}$ at 60 days and at 1 year after hospital discharge. The questionnaire included the following aspects: whether any health service was used after hospital discharge; whether they were public or private services; the type of health service: outpatient clinic, emergency (emergency care), urgent care (immediate care services, located in the northern and southern part of the city), health units (such as Basic Health Units or Family Health Strategies) emergency home care (from public or private hospitals); and whether the elderly was readmitted during this period after discharge. Data collection took place from May 2016 to July 2018.

For the descriptive analysis, means and standard deviations or the median and the interquartile range were calculated for quantitative variables. For qualitative variables, absolute and relative frequencies were presented. In order to compare the control and intervention groups regarding socio-demographic characteristics, health condition and use of health services, the Student's T-test was used for continuous variables with normal distribution, or the Mann-Whitney U-test was used when asymmetric. The Pearson's chi-square or the Fisher's exact test was used for categorical variables. A $p$-value $<0.05$ was considered significant. For the elderly considered a loss to follow-up, there was a bank verification regarding the "yes" answers about the use of health services and hospital readmission within 60 days after hospital discharge. Thus, the information of these participants was cumulative in the one-year assessment.

Participants signed a Free and Informed Consent Form. The study was approved by the Research Ethics Committee of the Hospital de Clínicas in Porto Alegre (No. 160181).

\section{口 RESULTS}

From May 2016 to June 2017, 471 patients were admitted to the UCE-AVC, of whom 245 were potentially eligible for the study. 197 were excluded. At the end, 48 participants were randomized, 24 to the IG and 24 to the CG. In the 60-day assessment after discharge, there were four losses to follow-up, resulting in 21 in the IG and 23 in the CG. One year after discharge, the IG had two other losses $(I G=19)$ and the $C G$ had six losses $(C G=17)$. The $R C T$ diagram is shown in Figure 1.

Table 1 presents the socio-demographic characteristics and health condition of the elderly post-stroke. There was a significant difference regarding marital status $(p=0.036)$.

Table 2 presents the socio-demographic characteristics, health condition and caregiver status of family caregivers of elderly people post-stroke. There was a statistically significant difference between the groups regarding gender $(p=0.050)$.

The use of health services by the elderly post-stroke is shown in Table 3. Sixty days after hospital discharge there was a difference regarding the use of the outpatient clinic between the groups $(p=0.050)$. 
Bierhals CCBK, Day CB, Mocellin D, Santos N0, Predebon ML, Dal Pizzol FLF, Fuhrmann AC, Medeiros GG, Aires M, Paskulin LMG

Figure 1 - RCT diagram according to the Consolidated Standards of Reporting Trials (CONSORT)

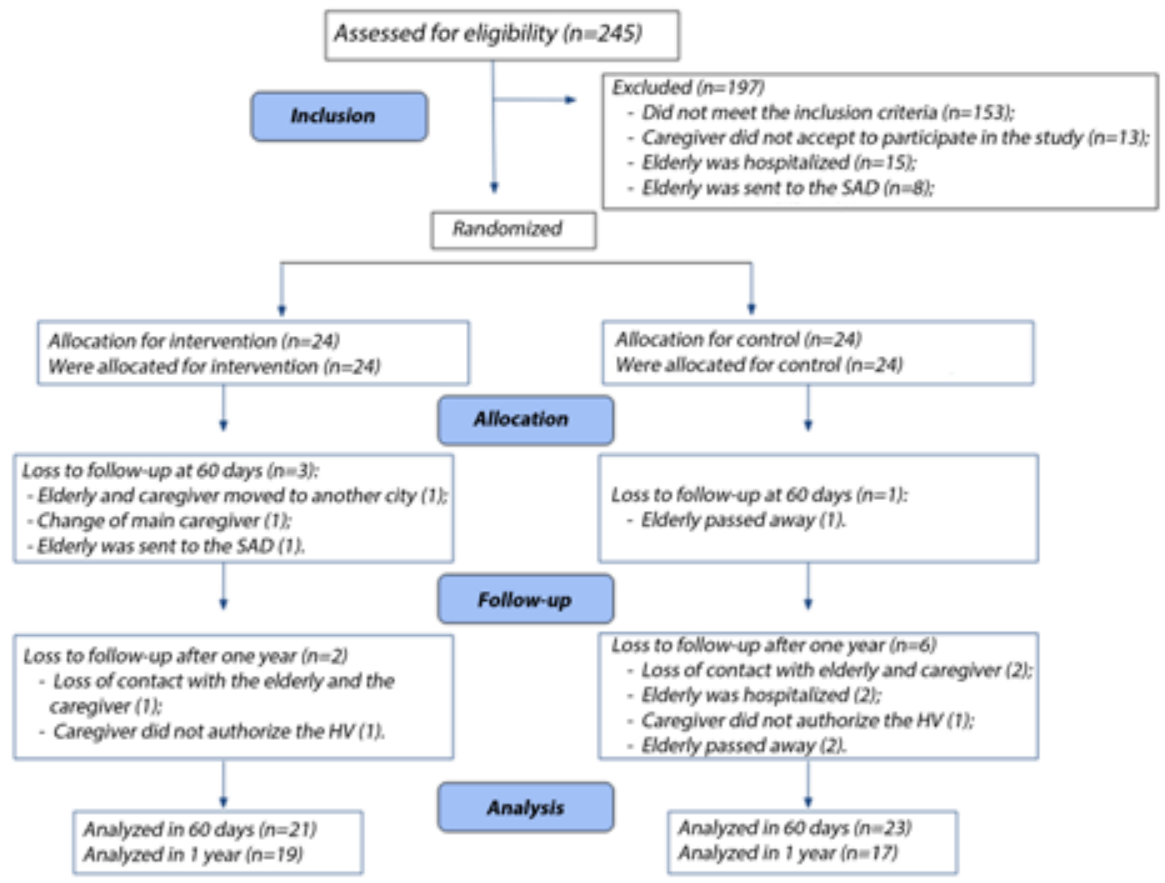

Table 1 - Socio-demographic characteristics and health condition of the elderly post-stroke participants of the SHARE, Porto Alegre/RS, 2019

\begin{tabular}{|c|c|c|c|}
\hline Variables & IG $(n=21)$ & CG $(n=23)$ & $\mathbf{P}$ \\
\hline Age (years old) ${ }^{*}$ & $72.95 \pm 10.2$ & $73.5 \pm 8.0$ & 0.310 \\
\hline \multicolumn{4}{|l|}{ Gender $(\%)^{+}$} \\
\hline Female & $13(62)$ & $11(47.8)$ & 0.526 \\
\hline Marital status (\%) ${ }^{\dagger}$ & & & 0.036 \\
\hline Married/Partner & $7(33.3)$ & $16(69.6)$ & \\
\hline Alone & $14(66.7)$ & $7(30.4)$ & \\
\hline Education (years) $^{\ddagger}$ & $4(2.5-5.0)$ & $5(3-8)$ & 0.151 \\
\hline Family income $^{\ddagger \S}$ & $1.760(1540-2200)$ & $2.200(1760-3520)$ & 0.164 \\
\hline Stroke $(\%)^{\dagger}$ & & & 1.000 \\
\hline Ischemic & $21(95.2)$ & $22(95.7)$ & \\
\hline \multicolumn{4}{|l|}{ Morbidities (\%) ${ }^{\dagger}$} \\
\hline Arterial hypertension & $18(85.7)$ & $21(91.3)$ & 0.455 \\
\hline Heart diseases & $5(23.8)$ & $4(17.4)$ & 0.438 \\
\hline Vascular disease & $4(19)$ & $4(17.4)$ & 1.000 \\
\hline mRankin score (\%) ${ }^{\dagger}$ & & & 0.723 \\
\hline Mild disability & $2(9.5)$ & $3(13)$ & \\
\hline Moderate disability & $16(76.2)$ & $15(65.2)$ & \\
\hline Severe disability & $3(14.3)$ & $5(21.7)$ & \\
\hline \multicolumn{4}{|l|}{ MIF functional capacity } \\
\hline Basal & $60.6 \pm 17$ & $60 \pm 22.2$ & 0.919 \\
\hline
\end{tabular}

Source: Research data, 2019.

"Variables expressed as mean \pm standard deviation, independent t-test

${ }^{\dagger}$ Absolute number and (\%), Pearson's chi-square test and Fisher's exact test

FMedian and $25^{\text {th }}$ and $75^{\text {th }}$ percentiles, Mann-Whitney test

SThe minimum wage at the time of data collection was $\$ \$ 937.00$ 
Table 2 - Socio-demographic characteristics, health condition and caregiver status of family caregivers of elderly people post-stroke participating in SHARE, Porto Alegre/RS,2018

\section{Variables}

IG $\mathbf{n = 2 1}$

CG $n=23$

$\mathbf{P}$

Gender (\%)*

\begin{tabular}{lccc}
\hline Female & $21(100)$ & $18(78.3)$ & 0.050 \\
\hline Age $^{\dagger}$ & $53.71 \pm 11.95$ & $52.96 \pm 14.06$ & 0.758 \\
\hline Education (years) $^{\ddagger}$ & $11(5-11.75)$ & $8(5-11)$ & 0.242 \\
\hline Professional status $^{\dagger}$ & & & 0.383 \\
\hline Active & $11(52.4)$ & $8(34.8)$ & \\
\hline Not active & $10(47.6)$ & $15(65.2)$ & \\
\hline
\end{tabular}

Marital status*

0.272

\begin{tabular}{|c|c|c|c|}
\hline Married/Partner & $15(71.4)$ & $20(87)$ & \\
\hline Alone & $6(28.6)$ & $3(13)$ & \\
\hline Relationship with the elderly & & & 0.107 \\
\hline Son & $11(52.4)$ & $5(21.7)$ & \\
\hline Spouse & $7(33.3)$ & $13(56.5)$ & \\
\hline Other & $3(14.3)$ & $5(21.7)$ & \\
\hline Health problems (yes) ${ }^{*}$ & $16(76.2)$ & $16(69.7)$ & 0.622 \\
\hline \multicolumn{4}{|l|}{ Morbidities (\%) } \\
\hline Hypertension & $9(43)$ & $9(49.1)$ & 1.000 \\
\hline Diabetes & $3(14.3)$ & $5(21.7)$ & 0.701 \\
\hline Resides with the elderly (yes) ${ }^{*}$ & $18(85.7)$ & $21(91.3)$ & 0.658 \\
\hline Received support to care after discharge (yes) & $18(85.7)$ & $21(91.3)$ & 0.658 \\
\hline \multicolumn{4}{|l|}{ Type of support received (\%) } \\
\hline Instrumental & $17(81)$ & $19(82.6)$ & 1.000 \\
\hline Emotional & $14(66.7)$ & $17(74)$ & 0.845 \\
\hline Financial & $8(31.1)$ & $10(43.5)$ & 0.955 \\
\hline
\end{tabular}

Source: Research data, 2018.

"Absolute number and (\%), Pearson's chi-square test and Fisher's exact test.

${ }^{\dagger}$ Variables expressed as mean \pm standard deviation, independent t-test.

${ }^{\prime}$ Median and $25^{\text {th }}$ and $75^{\text {th }}$ percentiles, Mann-Whitney test 
Table 3 - Use of health services by the post-stroke elderly participating in the SHARE, Porto Alegre/RS, 2019

\begin{tabular}{|c|c|c|c|c|}
\hline Variables* & Item & IG $n=21$ & CG $n=23$ & $\boldsymbol{P}$ \\
\hline \multirow{2}{*}{ Use of health service (yes) } & 60 days & $21(100)$ & $23(100)$ & - \\
\hline & 1 year & $21(100)$ & $23(100)$ & - \\
\hline \multicolumn{5}{|l|}{ Network service } \\
\hline \multirow{2}{*}{ Public } & 60 days & $21(100)$ & $23(100)$ & - \\
\hline & 1 year & $21(100)$ & $23(100)$ & - \\
\hline \multirow[t]{2}{*}{ Private } & 60 days & $5(23.8)$ & $7(30.4)$ & 0.878 \\
\hline & 1 year & $7(36.8)$ & $9(50)$ & 0.634 \\
\hline \multicolumn{5}{|l|}{ Type of health service } \\
\hline \multirow[t]{2}{*}{ Outpatient clinic } & 60 days & $21(100)$ & $18(78.3)$ & 0.050 \\
\hline & 1 year & $21(100)$ & $20(95.2)$ & 1.000 \\
\hline \multirow[t]{2}{*}{ Emergency } & 60 days & $3(14.3)$ & $5(21.7)$ & 0.701 \\
\hline & 1 year & $6(31.6)$ & $5(29.4)$ & 1.000 \\
\hline \multirow[t]{2}{*}{ Urgent care } & 60 days & $4(19.0)$ & $1(4.3)$ & 0.176 \\
\hline & 1 year & $4(21.1)$ & $4(23.5)$ & 1.000 \\
\hline \multirow[t]{2}{*}{ Health facility } & 60 days & $14(66.7)$ & $16(69.6)$ & 1.000 \\
\hline & 1 year & $19(89.5)$ & $21(93.8)$ & 0.607 \\
\hline \multirow{2}{*}{$\begin{array}{l}\text { Urgent } \\
\text { home care }\end{array}$} & 60 days & $1(4.8)$ & $1(4.3)$ & 1.000 \\
\hline & 1 year & $3(15.8)$ & $3(17.6)$ & 1.000 \\
\hline \multirow[t]{2}{*}{ Hospital readmission (yes) } & 60 days & $4(19)$ & $2(8.7)$ & 0.403 \\
\hline & 1 year & $8(40)$ & $5(31.25)$ & 0.846 \\
\hline
\end{tabular}

"Absolute number and (\%), Pearson's chi-square test and Fisher's exact test.

\section{DISCUSSION}

This is the first RCT to assess the use of health services by the elderlies post-stroke and their readmissions conducted in Brazil(15). Sixty days after discharge, there was a statistically significant difference regarding the use of outpatient service between the groups. One of the actions of the SHARE's interventionist nurses was to reinforce, to the elderly and caregivers, the importance of outpatient follow-up for periodic evaluations of the elderly's health condition, examinations and medication adjustments, if necessary. It is believed that this aspect may have contributed to the increased use of this service by the IG.

An RCT conducted in Germany also identified greater use of outpatient services by elderly stroke patients who received intervention through a hospital-to-home care transition program. The program consisted of educational interventions for family caregivers by nurses and physiotherapists addressing individual training on home care before discharge, available support network (outpatient service and support groups), and seminars on the disease. In addition, they received orientation through phone calls three months after discharge. The authors state that this result provides an opportunity to reduce home care-related complications due to frequent follow-up with professionals of the outpatient service ${ }^{(8)}$. The use of outpatient services enable the connection between the patients and the resources available after discharge ${ }^{(16)}$.

Although access to primary care health services was also reinforced by interventionist nurses, there was no difference regarding the use of the health unit between the groups. However, it was the second most popular health service between both groups. It is noteworthy that all the elderlies and their caregivers received guidance from the multidisciplinary team of UCE-AVC regarding the use of services in the primary health care network to which the patient had access. This aspect is believed to have influenced the results. In addition, regardless of the intervention, all elderlies with a stroke were expected to be followed-up by primary health care services after hospital discharge. These services should act as the main gateway and communication center of the Health Care Network (Rede de Atenção à Sáude, RAS), acting as the coordinator of the services available in the network, promoting 
improvements in the quality of the services offered and expanding access to different levels of care ${ }^{(17)}$.

For the transition from hospital care to the home of dependent elderly patients post-stroke, the services need to be articulated and should continue care, according to the complexity of the case. In Brazil, some public policies have been implemented to ensure the continuity of care and to meet the demands of patients and caregivers. In this sense, Home Care ( $\mathrm{HC}$ ) aims to articulate the points of attention in the service network in order to expand the integrity of care. In addition, it systematizes care for the dependent elderly, identifying their needs and those of their families to avoid health complications and readmissions ${ }^{(1)}$.

In the international scenario, there are structured models with a wide network of health services for the elderly population based on primary health care and on $\mathrm{HC}$. A critical literature review evaluating the effectiveness of care networks integrated with this group, especially in the United States and Canada, identified that the integration between different levels of care decreases the use of hospital services by the elderly. Day care centers, home services, social services and a single electronic medical record are some of the examples of this articulation between the network ${ }^{(18)}$.

Regarding the use of hospital emergency services, emergency home care and urgent care, there was no statistically significant difference between the groups, although these services were the least popular among the IG and the CG. In China, a care transition program assessing the effects of an intervention made by nurses with assistance of a multidisciplinary team to stroke patients and their caregivers found a statistically significant difference regarding the use of emergency services between the groups at eight weeks after discharge ( $\mid \mathrm{G}=1.9 \%, \mathrm{CG}=13 \%, \mathrm{p}=0.027)$. The intervention consisted of meetings with the patients' families, HVs and telephone calls for four weeks after discharge. It addressed aspects of emotional and psychological support, guidance on the disease, medications, diet and physical rehabilitation of the patient ${ }^{(10)}$. It is to be noted that, unlike SHARE, this intervention addressed the physical rehabilitation of the patient and was supported by a multidisciplinary team with a mixed approach between HVs and telephone contact. It is believed that these particularities may have influenced the diversity among the results.

Regarding hospital readmission, there was no difference between the groups. In the international context, an $\mathrm{RCT}$ conducted in India found similar results. The program was conducted by a multidisciplinary team for post-stroke patients and their family caregivers. The intervention group received structured rehabilitation training on activities of daily living, such as positioning, transfer, eating, dressing, motor activity, and information about stroke. Training began at the hospital and continued at home for up to 2 months after discharge. In 6 months of follow-up, there was no difference between the groups regarding readmission (89 [14\%] IG vs. 82 [13\%] CG; $p=0.560)^{(19)}$. In England, another RCT that also offered an educational intervention in nursing techniques and skills training found no difference in readmission rates between groups at six and 12 months of evaluation ${ }^{(20)}$.

In contrast, a care transition program conducted in Australia was effective in reducing hospital readmission rates $(\mathrm{IG}=22 \%, \mathrm{CG}=47 \%, \mathrm{p}<0.007)$ and in the use emergency services ( $I G=25 \%, C G=67 \%, p<0.001)$. The intervention was based on physical therapy exercises during hospitalization, nursing follow-up through HVs and telephone contact within 24 weeks after discharge $\mathrm{e}^{(9)}$. Similarly to the study previously discussed, it is clear that this research had a mixed approach and was supported by a team of nurses and physiotherapists. It is believed that the team approach and composition may have contributed to the disparity in results with the Australian study.

\section{- CONCLUSION}

The IG showed greater use of the outpatient service. This aspect may indicate the link between this group and the service recommended for continuity of treatment after hospital discharge, demonstrating the effectiveness of the intervention through educational nursing interventions at home. However, a greater integration between the different points of the RAS is necessary, based on an effective referral and counter-referral system, which promotes communication among the professionals working in different health services and thus, meeting the needs of the elderly with a stroke and their families after hospital discharge and the return to their homes.

In addition, the importance of expanding the services that make up the RAS, such as day care centers, and greater access to home care, both by APS and SAD, is reinforced. New studies should evaluate the effectiveness of educational nursing interventions regarding the use of $\mathrm{HC}$ services in the country.

This study has some limitations that interfere with the generalization of the results. The population belongs to a certain region of the country, with distinct social and economic peculiarities when compared to other regions of Brazil. In addition, the sample was not calculated for this outcome, thus requiring a larger sample of the population studied. Moreover, the reason that led the elderly with a 
stroke to use the health service, as well as the satisfaction of the services used, was not evaluated. Participants were selected from a special stroke care unit and received differentiated follow-up care for these patients differently from other services in the country. Further studies are suggested in different regions of Brazil, with a larger sample and in different health services that address these aspects.

\section{口 REFERENCES}

1. Rodrigues RAP, Marques S, Kusumota L, Santos EB, Fhon JRS, Fabrício-Wehbeet SCC. Transição do cuidado com o idoso após acidente vascular cerebral do hospital para casa. Rev Latino-Am Enfermagem. 2013;21(spe)-216-24. doi: https://doi.org/10.1590/S0104-11692013000700027.

2. Silva AMM, Mambrini JVM, Peixoto SV, Malta DC, Lima-Costa MF. Uso de serviços de saúde por idosos brasileiros com e sem limitação funcional. Rev Saude Pública. 2017;51Sup 1:5s. doi: https://doi.org/10.1590/S15188787.2017051000243.

3. Rohweder G, Salvesen O, Ellekjær H, Indredavik B. Hospital readmission within 10 years post stroke: frequency, type and timing. BMC Neurol. 2017;17:116. doi: https://doi.org/10.1186/s12883-017-0897-z.

4. Prvu BJ, McCoy L, Smith EE, Fonarow GC, Schwamm LH, Peterson ED, et al. Contemporary trends and predictors of post acute service use and routine discharge home after stroke. J Am Heart Assoc. 2015;4 (2):e001038. doi: https://doi.org/10.1161/JAHA.114.001038.

5. Hsieh $C Y$, Lin HJ, Hu YH, Sung SH. Stroke severity may predict causes of readmission within one year in patients with first ischemic stroke event. J Neurol Sci 2017;372:21-7. doi: https://doi.org/10.1016/j.jns.2016.11.026.

6. Cameron II, O'Connell C, Foley N, Salter K, Booth R, Boyle R, et al. Canadian stroke best practice recommendations: managing transitions of care following Stroke, Guidelines Update. Int J Stroke. 2016 0ct;11(7):807-22. doi: https://doi. org/10.1177/1747493016660102.

7. Shepperd S, Lannin NA, Clemson LM, McCluskey A, Cameron ID, Barras SL. Discharge planning from hospital to home. Cochrane Database Syst Rev. 2013; 1:1-14. doi: https://doi.org/10.1002/14651858.CD000313.

8. Gräsel E, Biehier J, SchmidtR, SchuppW. Intensification of the transition between inpatient neurological rehabilitation and home care of stroke patients: controlled clinical trial with follow-up assessment six months after discharge. Clin Rehabil. 2005;19(7):725-36. doi: https://doi.org/10.1191/0269215505cr900oa.

9. Courtney M, Edwards H, Chang A, Parker A, Finlayson $K$, Hamilton $K$, et al. Fewer emergency readmissions and better quality of life for older adults at risk of hospital readmission: a randomized controlled trial to determine the effectiveness of a 24-week exercise and telephone follow-up program. J
Am Geriatr Soc. 2019;57(3):395-402. doi: https://doi.org/10.1111/j.15325415.2009.02138.x

10. Wong FK, Yeung SM. Effects of a 4-weeks transitional care programme for discharge stroke survivors in Hong Kong: a randomised controlled trial. Health Soc Care Community. 2015;23(6):619-31. doi: https://doi.org/10.1111/ hsc. 12177.

11. Occelli P, Touzet S, Rabilloud M, Ganne C, Poupon Bourdy S, Galamand B, et al. Impact of a transition nurse care program on the prevention of thirty-day hospital readmissions of elderly patients discharged from short-stay units: study protocol of the PROUST stepped-wedge cluster randomised trial. BMC Geriatr. 2016;16:57. doi: https://doi.org/10.1186/s12877-016-0233-2.

12. Duncan PW, Bushnell CD, RosamondWD, Jones Berkeley SB, Gesell SB, D'Agostino RB Jr., et al. The Comprehensive Post-Acute Stroke Services (COMPASS) study: design and methods for a cluster-randomized pragmatic trial. BMC Neurol. 2017;17(1):133. doi: https://doi.org/10.1186/s12883-017-0907-1.

13. Bierhals CCBK. Efeito da Nursing Home Care Intervention Post Strokena qualidade de vida de cuidadores familiares de idosos: ensaio clínico randomizado [tese]. Porto Alegre (RS): Universidade Federal do Rio Grande do Sul; 2019.

14. Van Swieten JC, Koudstaal PJ, Visser MC, Schouten HJ, van Gijn J. Interobserver agreement for the assessment of handicap in stroke patients. Stroke. 1988;19(5):604-7. doi: https://doi.org/10.1161/01.STR.19.5.604.

15. Day CB, Bierhals CCBK, Santos NOD, Mocellin D, Predebon ML, Dal Pizzol FLF, et al. Nursing home care educational intervention for family caregivers of older adults post stroke (SHARE): study protocol for a randomised trial. Trials. 2018;19(1):96. doi: https://doi.org/10.1186/s13063-018-2454-5.

16. Bakas T, Clark PC, Kelly-Hayes M, King RB, Lutz BJ, Miller EL, et al. Evidence for stroke family caregiver and dyad interventions. Stroke. 2014; 45(9):2836-52. doi: https://doi.org/10.1161/STR.0000000000000033.

17. Almeida PF, Medina MG, Fausto MCR, Giovanella L, Bousquat A, Mendonça MHM. Coordenação do cuidado e Atenção Primária à Saúde no Sistema Único de Saúde. Saúde Debate. 2018; 42(spec):244-60. doi: https://doi. org/10.1590/0103-11042018s11.

18. Veras RP, Caldas CP, Motta LB, Lima LC, Siqueira RC, Rodrigues RTSV, et al. Integração e continuidade do cuidado em modelos de rede de atenção à saúde para idosos frágeis. Rev Saúde Pública. 2014; 8(2):357-65. doi: http://doi. org/10.1590/S0034-8910.2014048004941.

19. ATTEND Collaborative Group. Family-led rehabilitation after stroke in India (ATTEND): a randomised controlled trial. Lancet. 2017;390(10094):588-99. doi: https://doi.org/10.1016/S0140-6736(17)31447-2.

20. Forster A, Dickerson J, Young J, Patel A, Kalra L, Nixon J, et al. A structured training programme for caregivers of inpatients after stroke (TRACKS): a cluster randomised controlled trial and cost-effectiveness analysis. Lancet. 2013;382(9910):2069-76. doi: https://doi.org/10.1016/S01406736(13)61603-7.

Received: 04.23.2019

Approved: 05.30.2019

Carla Cristiane Becker Kottwitz Bierhals

E-mail: carlakot@yahoo.com.br 